\title{
Comparative study of analgesic effect of intrathecal bupivacaine and bupivacaine with fentanyl during and after cesarean delivery
}

\author{
Uike $\mathbf{S}^{1}$, Choudhary $\mathbf{S}^{2,}$ Jain $\mathbf{A}^{3}$ \\ ${ }^{1}$ Dr Satyendra Uike, Assistant Professor, ${ }^{2}$ Dr Shashibala Choudhary, Senior Resident, ${ }^{3}$ Dr Amit Jain, Assistant Professor. \\ All are affiliated to Department of Anesthesiology, Bundelkhand Medical College Sagar, MP, India
}

Address for correspondence: Dr Satyendra Uike, Email: last21dream@ yahoo.com

\begin{abstract}
Introduction: Neuraxial administration of opioids added to local anesthetics improves the quality of intraoperative analgesia and also provides postoperative pain relief for long duration. The aim of our study was to compare the analgesic effect of subarachnoid block with $10 \mathrm{mg}, 0.5 \%$ hyperbaric bupivacaine with combination of $10 \mathrm{mg}, 0.5 \%$ hyperbaric bupivacaine and $12.5 \mu \mathrm{g}$ fentanyl in parturient posted for elective caesarean section. Methods: All the parturient of ASA grade 1 and 2 were randomized allocated into two groups of 40 each. Group B received 10mg of $0.5 \%$ hyperbaric bupivacaine and group BF received 10mg $0.5 \%$ hyperbaric bupivacaine with $12.5 \mu \mathrm{g}$ fentanyl. Characteristics of sensory and motor blockade with hemodynamic parameters were observed, recorded intraoperative and postoperatively. Results: $10 \mathrm{mg}$ of $0.5 \%$ bupivacaine with $12.5 \mu \mathrm{g}$ fentanyl produces effective level of sensory blockade and less intensive motor blockade, maintains stable intraoperative hemodynamic parameters with decrease incidences of adverse effects like nausea and vomiting, shivering. The total duration of effective analgesia was significantly longer in fentanyl group. Pruritus was significant side effect in fentanyl group. Conclusion: Intrathecal fentanyl in dose of $12.5 \mu \mathrm{g}$ of fentanyl with bupivacaine for spinal anesthesia in caesarean section provides good intraoperative and significantly reduces the demand for postoperative analgesic with good maternal satisfaction and foetal well being.
\end{abstract}

Key words: Intrathecal fentanyl, Hyperbaric bupivacaine, Postoperative analgesia

\section{Introduction}

Spinal anaesthesia is the preferred means for cesarean delivery. It carries high efficiency, minimal neonatal depression, awake mother and lesser incidence of aspiration pneumonitis [1,2,3]. The technique of subarachnoid block is quite simple and single injection results in ideal operating conditions with complete analgesia, profound muscular relaxation, decreased blood loss and minimal ventilatory disturbances.

Further, in a developing area like Bundelkhand, non availability of highly sophisticated anaesthetic equipment and compressed gases with their prohibitive cost makes spinal anaesthesia one of the major tools in the hands of an anesthesiologist. If we can extend its duration to include the postoperative period it will be unmatched.

Cesarean delivery patients have even more compelling

Manuscript received: $2^{\text {nd }}$ Feb 2015

Reviewed: $17^{\text {th }}$ Feb 2015

Author Corrected: $4^{\text {th }}$ Mar 2015

Accepted for Publication: $14^{\text {th }}$ Mar 2015 reasons to achieve optimal postoperative pain relief than any other surgical patients and they also present with unique challenges. Post cesarean delivery patients are at higher risk for thromboembolic events which may also be precipitated by immobility from inadequate pain control [4,5] or excessive sedation from opioids. Moreover these women need to ambulate, to be alert and energetic enough to care for, interact with and breastfeed their new born. Early breastfeeding is important immediately after childbirth to promote and improve mother bonding and enhances puerperal changes to regain prepregnancy state $[6,7]$.

With these goals in mind, the analgesic of choice require minimal transfer in breast milk, little or no effect on neonates, minimal maternal side effects and minimal or no interference with caring for the newborn or discharge from hospital. The common modalities are systemic administration of opioids, either by intramuscular injection or i.v. injection, by patient controlled analgesia or by neuraxial injection of opioids as part of regional

Available online at: www.ijmrr.in 256 | P a g e 
anaesthetic for postoperative analgesia in cesarean delivery.

Fentanyl is a synthetic primary $\mu$-opioid agonist. Chemically it is N-phenyl-N-(1-phenethyl-4piperadenyl) and was first synthesized by Dr.Paul Janssen in 1959. In 1960 fentanyl was introduced as an intravenous anaesthetic under the name of sublimaze. In Mid 1990, duragesic patch of fentanyl was introduced in to clinical trial. Now fentanyl is given via various routes i.e. transdermal, i.v., i.m., oral, sublingual, buccal, intrathecal, epidural [8].

The purpose of this study was to compare the analgesic effect of intrathecal bupivacaine and bupivacaine with fentanyl during \& after cesarean delivery.

\section{Material and Methods}

A double -blinded prospective randomized control clinical study was planned $\mathrm{f}$ or one year on full term parturient scheduled for elective cesarean section delivery under spinal anesthesia at Bundelkhand medical college and associate hospitals, sagar. After obtaining approval from the institutional Ethics committee, 80 parturient of ASA physical status I \& II, aged between 20 and 30 years were enrolled for this study.

Written informed consent was obtained from all study participants after describing all aspects of the study. Patients were randomly allocated according to a computer generated random table into 2 groups of 40 each.

Control group B $(\mathrm{n}=40)$ received intrathecally $10 \mathrm{mg}(2$ $\mathrm{ml}$ ) of $0.5 \%$ hyperbaric bupivacaine with $0.25 \mathrm{ml}$ of normal saline.

Case group $\mathrm{BF}(\mathrm{n}=40)$ received intrathecally $10 \mathrm{mg}(2$ $\mathrm{ml})$ of $0.5 \%$ hyperbaric bupivacaine with of $12.5 \mu \mathrm{g}$ $(0.25 \mathrm{ml})$ preservative free fentanyl.

Patients in whom regional anaesthesia is contraindicated, complicated pregnancies such asmultiple pregnancies, placenta previa, and pregnancy induced hypertension, patients with acute fetal distress $\&$ fetal abnormalities and unable to understand the visual analogues were excluded from the study.

In all patients ,baseline value of $\mathrm{BP}, \mathrm{HR}, \mathrm{SpO}_{2}$ and $\mathrm{RR}$ were recorded and preoperatively preloading with 15-20 $\mathrm{ml} / \mathrm{kg}$ of Ringer lactate and received inj. ranitidine 50 $\mathrm{mg}$ and metoclopramide $10 \mathrm{mg}$ intravenously as premedication . Under all aseptic precautions, subarachnoid block was given in lateral position via midline approach in L3-L4 interspinous space with Quinckes spinal needle $25 \mathrm{G}$. After confirmation of free flow of cerebrospinal fluid, drug prepared as per group of patients was injected with a uniform speed. After noting the time of injection patient was immediately placed in supine position thereafter with left uterine displacement. All patients received supplemented oxygen. The characteristic of sensory blockade was assessed by pin prick method and Motor blockade was assessed by Bromage Scale [9].

Bromage grade 1- free movements of legs and feet,

Bromage 2 -just able to flex knees with free movements of feet,

Bromage 3- the patient is unable to flex knees, but with free movements of feet,

Bromage 4- is unable to move legs and feet.

Intra-operatively, patients were monitored for heart rate, blood pressure and respiratory rate and $\mathrm{SPO}_{2}$ every 2 min for first $10 \mathrm{~min}$ and then every $5 \mathrm{~min}$ up to first hour and every $30 \mathrm{~min}$ thereafter up to 270 minutes. The patients were monitored in the post-anaesthesia care unit. Time taken for recovery of sensory level to two dermatome segments below the highest level was noted. Postoperatively the patients were evaluated for pain at the operation site with visual analogue scale 0 to $10(0=$ No pain, $10=$ Worst pain $)[10]$. Time interval between injection of spinal drug to first reports of pain was noted i.e. considered as the duration of complete sensory analgesia. Rescue analgesic as inj. Tramadol 50 mg i.v. given when VAS was more than 4. Time taken from the administration of subarachnoid block to the patient's first on demand analgesic drug for pain was noted i.e. considered as the duration of effective analgesia.

Side effects such as Pruritus (rated as none, minimal, moderate and severe), hypotension (fall of more than $20 \%$ from baseline systolic reading), nausea/vomiting, shivering, respiratory depression or bradycardia (heart rate $<60$ per min) and apgar score of the newborns at 1 minute and 5 minutes were noted.

The data of the present study were analyzed using the software SPSS 11.5 for windows. Appropriate univariate and bivariate analysis were carried out using the Student $t$ test for the continuous variable (age) and two-tailed Fisher exact test or chi-square $\left(\chi^{2}\right)$ test for 
categorical variables. All means are expressed as mean \pm standard deviation. The critical levels of significance of the results were considered at 0.05 levels i.e. $P<0.05$ was considered significant.

\section{Results}

The demographic data in terms of age distribution, weight, height and duration of surgery in both groups were comparable and statistically in significant. (Table No.1)

\begin{tabular}{|l|l|l|l|l|}
\hline Table No.1. Demographic data $($ Mean \pm SD) \\
\hline Variable & Group B $(\mathbf{n}=\mathbf{4 0})$ & $\begin{array}{l}\text { Group BF } \\
(\mathbf{n}=\mathbf{4 0})\end{array}$ & p-value & Un paired t value \\
\hline Age $($ Yrs $)$ & $24.85 \pm 1.9$ & $25.15 \pm 2.29$ & 0.5256 & 0.63 \\
\hline Weight $(\mathrm{Kg})$ & $59.10 \pm 3.33$ & $58.7 \pm 3.59$ & 0.6069 & 0.51 \\
\hline Height $(\mathrm{Cm})$ & $152.13 \pm 2.23$ & $151.78 \pm 2.03$ & 0.4651 & 0.73 \\
\hline $\begin{array}{l}\text { Duration of } \\
\text { surgery(Mins) }\end{array}$ & $60.50 \pm 9.2$ & $60.70 \pm 7.9$ & 0.9172 & 0.10 \\
\hline
\end{tabular}

The onset of sensory analgesia at T10 was comparable and found statistically insignificant in both the groups but time to achieve highest level of sensory analgesia and time taken for two segment regression was significantly prolonged in fentanyl . Time to achieve grade 3 motor block was earlier in group BF compare to group B. The mean onset of motor block was $3.10( \pm 0.74)$ minutes in group B, while in group BF it was 2.33( \pm 0.62$)$ minutes, this difference was statistically significant. The difference in the mean time of total duration of grade 3 motor block in Group B (109.88 \pm 17.81$)$ and Group BF (113.38 \pm 37.9$)$ was statistically not significant.

\begin{tabular}{|l|l|l|l|l|}
\hline \multicolumn{1}{|l|}{ Table No.2: Characteristics of sensory, motor block and regression time (Mean \pm SD) } \\
\hline & $\begin{array}{l}\text { Group B } \\
(\mathrm{n}=40)\end{array}$ & $\begin{array}{l}\text { Group BF } \\
(\mathrm{n}=40)\end{array}$ & p-value & $\begin{array}{l}\text { Un paired t } \\
\text { value }\end{array}$ \\
\hline $\begin{array}{l}\text { Onset of sensory analgesia at } \\
\text { T10 (Mins) }\end{array}$ & $1.8 \pm 0.5$ & $1.66 \pm 0.38$ & 0.1625 & 1.41 \\
\hline $\begin{array}{l}\text { Time to achieve highest level of } \\
\text { sensory analgesia (Mins) }\end{array}$ & $6.8 \pm 0.88$ & $6.23 \pm 0.89$ & 0.0051 & 2.88 \\
\hline $\begin{array}{l}\text { Time for two segment regression } \\
\text { (Mins) }\end{array}$ & $86.63 \pm 17.11$ & $114.75 \pm 37.52$ & 0.0001 & 4.31 \\
\hline Onset of grade III motor block & $3.10 \pm 0.74$ & $2.33 \pm 0.62$ & 0.0001 & 5.04 \\
\hline $\begin{array}{l}\text { Total duration of grade III motor } \\
\text { block }\end{array}$ & $109.88 \pm 17.81$ & $113.38 \pm 37.9$ & 0.5986 & 0.5286 \\
\hline $\begin{array}{l}\text { Duration of complete analgesia } \\
\text { Duration of effective analgesia }\end{array}$ & $170 \pm 28.42$ & $259.63 \pm 36.35$ & 0.0001 & 12.28 \\
\hline $\begin{array}{l}\text { Time between intrathecal } \\
\text { injection to delivery interval }\end{array}$ & $6.53 \pm 1.24$ & $260.13 \pm 33.71$ & 0.0001 & 12.10 \\
\hline
\end{tabular}

Intrathecal fentanyl with bupivacaine significantly improved the quality of intraoperative surgical anesthesia as none of the patient complained of discomfort in intraoperative period and the total duration of complete analgesia and effective analgesia was statistically significantly prolonged in group BF as compare to group B. (Table No. 2)

Neonatal neurobehavioral assessment was done by Apgar score at 1 and 5minutes after delivery which was comparable in both groups and found statistically insignificant. None of the neonates had respiratory depression and bradycardia.

\begin{tabular}{|l|l|l|l|}
\hline \multicolumn{2}{|l|}{ Table No. 3: The neonatal outcome as assessed by APGAR score } & p-value \\
\hline Apgar score at & Group B & Group BF & $0.15 \mathrm{NS}$ \\
\hline $1 \mathrm{MIN}$ & $7.9 \pm 0.38$ & $7.75 \pm 0.54$ & \\
\hline $5 \mathrm{MIN}$ & $10 \pm 0.00$ & $10 \pm 0.00$ & \\
\hline
\end{tabular}


After subarachnoid block, initially fall in pulse rate per minute and fall in blood pressure was observed in the both groups but the mean value of mean arterial pressure and mean pulse rate changes per minute were similar and found statistically insignificant.

\begin{tabular}{|c|c|c|c|c|c|c|}
\hline & \multicolumn{2}{|c|}{ Group B } & \multicolumn{2}{|c|}{ Group BF } & \multirow{2}{*}{$\mathrm{P}$ value } & \multirow{2}{*}{ Inference } \\
\hline & $\mathrm{N}$ & $\%$ & $\mathrm{~N}$ & $\%$ & & \\
\hline Hypotension & 16 & 40 & 16 & 40 & $\mathrm{P}>0.05$ & NS \\
\hline Bradycardia & 5 & 12.5 & 4 & 10 & $\mathrm{P}>0.05$ & NS \\
\hline Nausea and Vomiting & 10 & 25 & 3 & 7.5 & $\mathrm{P}<0.05$ & $\mathrm{~S}$ \\
\hline Respiratory Depression & & 0 & & 0 & & \\
\hline Shivering & 8 & 20 & 2 & 5 & $\mathrm{P}<0.05$ & $\mathrm{~S}$ \\
\hline Pruritus & 0 & 0 & 3 & 8 & $\mathrm{P}<0.05$ & $\mathrm{~S}$ \\
\hline $\begin{array}{l}\text { Post dural puncture headache and } \\
\text { Neurological Complication }\end{array}$ & - & & & & & \\
\hline Foetal bradycardia & 0 & & 0 & & & \\
\hline
\end{tabular}

In group B, nausea, vomiting (25\%) and shivering (20\%) were the statistically significant side effects. The incidence of pruritus $(8 \%)$ was significantly higher in group BF as compare group B, however it subsided without any treatment.

None of the patients complained of respiratory depression, postdural puncture headache or neurological complication in the Group B and Group BF.

\section{Discussion}

The use of neuraxial opioids have increased dramatically over the last few years. They improve the quality of intraoperative analgesia produced by local anaesthetics, by binding directly with spinal opiate receptors and prolong the duration of postoperative analgesia. Opioids administered in the subarachnoid space appear to act principally on $\mu$-receptor in the substantia geletinosa of the dorsal horn of spinal cord by suppressing excitatory neuropeptide release from cfibers [11]. The combination of local anaesthetic and opioids, allow for a reduction in doses of both classes of drugs, thus lessening the side effects attributable to each.

Fentanyl, a lipophilic opioid has rapid onset of action following intrathecal administration, provides better intraoperative analgesia and is a safer alternative than morphine for management of early post operative pain as it does not migrate to fourth ventricle in sufficient concentration to cause delayed respiratory depression when administered intrathecally [12].

In our studies, fentanyl $12.5 \mu \mathrm{g}$ prolongs the duration of bupivacaine induced sensory blockade (sensory regression to L1 dermatome).
The mean time of onset of sensory block in group B was $1.80( \pm 0.50)$ minutes while it was $1.66( \pm 0.38)$ minutes in group $\mathrm{BF}$ and the difference was not statistically significant. ( $p>0.05)$. Our results concur with the past studies $[13,14,15]$. In group BF, $72.5 \%$ of patients achieved the highest level of sensory analgesia in the mean time in of $6.8 \pm 0.88$ minutes as compared to only $45 \%$ of patients in group B where mean time was 6.23 \pm 0.89 minutes, which was statistically significant. The high lipid solubility coupled with great affinity for $\mu$ receptors are pharmacokinetic characteristics able to explain the decrease in latency of local anesthetics and rapid installation of sensory block [16]. There is a potential synergism between fentanyl and bupivacaine, as reported in animal study by Wang et al [17].

The mean time interval for regression of two dermatome segment below the highest level were prolonged in fentanyl group which corroborated with observations of Biswas et al [14] and Benhamou D et al [18]' Herbhej S et al [19] study.

In our study, onset of grade 3 motor blocks was earlier in group BF but total duration of grade 3 motor block was comparable and found statistically in significant in both groups. Ben David et al [20] found enhanced sensory blockade without increased intensity of motor block or prolonged recovery for ambulatory discharge 
with $10 \mu \mathrm{g}$ fentanyl added with $5 \mathrm{mg}$ hyperbaric bupivacaine.

Chilvers et al observed improved intraoperative analgesia and prolonged sensory block in the $25 \mu \mathrm{g}$ fentanyl group but no difference in motor recovery similarly in our studies the mean duration of complete analgesia and time for effective analgesia was prolonged in Group BF when compared to Group B [21].

No significant difference in apgar score at 1 and 5 minutes were observed in both the groups which were similar with observation in studies of Atanas sivevski [22]' Shrivastava et $\mathrm{al}^{23}$ and Bogra et a[2].

Bradycardia was observed in $12.5 \%$ patients in Group $\mathrm{B}$ and $10 \%$ of patients in Group BF, and these patients responded to treatment with injection atropine $0.6 \mathrm{mg}$ IV. Hypotension was observed in $40 \%$ of the patients in Group B and $40 \%$ of the patients in Group BF and these patients were treated with $6 \mathrm{mg}$ of injection mephentermine IV and rapid infusion of IV fluids. The mean values of pulse rate changes per minute recorded in Group B and Group BF were almost similar and were statistically not significant. Atanas Sivevski [22] suggested that spinal anesthesia for cesarean delivery using $9 \mathrm{mg}$ isobaric bupivacaine plus $20 \mu \mathrm{g}$ fentanyl is associated with significantly less hypotension, vasopressor requirements and nausea than spinal anesthesia with $13.5 \mathrm{mg}$ of isobaric bupivacaine, without untoward effects.

Jaishri Bogra et al [2] in their study found that blood pressure declined, with increasing concentration of bupivacaine and fentanyl.

The study of Chow TC et al [24] concluded that low dose intrathecal fentanyl $12.5 \mu \mathrm{g}$ is a good method for decreasing both incidence \& severity of shivering during spinal anaesthesia.

In study by Theodore R.Manullang et al [25] and G. Dahlgren et al [26], observed that intrathecal fentanyl with hyperbaric bupivacaine for caesarian section reduces the need of intraoperative anti emetic medication. Similarly in our studies there was less incidence nausea and vomiting in group BF.

In our studies, incidence of pruritus was higher in group $\mathrm{BF}$, however it was not intense to be treated. Siddik Sajjid et al [27] also observed pruritus in $26 \%$ of patients in intrathecal fentanyl group. In the present study we did not notice any incidence of respiratory depression up to 24 hours postoperatively. Similar results of, no incidence of respiratory depression was noticed in the studies conducted by Biswas et al [14], Hunt Catherine O et al [15] and Singh H et al [19].

None of the patients in this study experienced any neurological complication during postoperative followup.

\section{Conclusion}

From the present study, we concluded that Intrathecal fentanyl as an adjuvant to intrathecal hyperbaric bupivacaine $(0.5 \%)$ in a dose of $12.5 \mu \mathrm{g}$ - provides significant prolongation of duration of sensory block with less intense motor blockade and effective analgesia with significantly decreases incidence of emetic episodes and shivering. Thus use of intrathecal fentanyl in a dose of $12.5 \mu \mathrm{g}$ will help in producing excellent quality and prolong the duration of analgesia with a single injection and with no adverse effect on mother and neonate.

\section{Funding: Nil}

Conflict of interest: None initiated. Permission from IRB: Yes

\section{References}

1. Datta, S. (2006).Anesthesia for cesarean delivery. Obstetric Anesthesia Handbook; 172-210.

2. Bogra J, Arora N, Shrivastava P. Synergistic effect of Intrathecal Fentanyl and Bupivacaine in spinal anesthesia for caesarean section. BMC Anesthesiology 2005 May 17; 5: 5. doi:10.1186/1471-2253-5-5

3. Rollins M, Lucero J.Overview of anesthetic considerations for Cesarean delivery. $\mathrm{Br}$ Med Bull. 2012;101:105-25. doi: 10.1093/bmb/ldr050. Epub 2012 Jan 4.

4. Frederick A, Anderson Jr, Frederick A, Spencer M. Four topics in venous thromboembolism. circulation 2003; 107:1-9-1-16. doi: 10.1161/01.CIR.0000078469.07362.E6

5. Aaro LA, Juergens JL. Thrombophlebitis associated with pregnancy. Am J Obstet Gynecol. 1971 Apr 15;109(8):1128-1136. 
6. Negishi H, Kishida T, Yamada H, Hirayama E et al; Changes in uterine size after vaginal delivery and cesarean section determined by vaginal sonography in the puerperium; Archives of Gynecology and Obstetrics;1999 Nov;263, (1-2):13-16 .doi: $10.1007 / \mathrm{s} 004040050253$.

7. Kuguoglu S, Yildiz H, Tanir MK, Demirbag BC. Breastfeeding after a Cesarean Delivery, Cesarean Delivery, Dr. Raed Salim (Ed.), ISBN: 978-953-510638-8, Available from:

http://www.intechopen.com/books/cesarean delivery/breastfeeding-after-a-cesarean-delivery.

8. Stanley TH. The history and development of the fentanyl series. J Pain Symptom Manage.1992 Apr; 7(3suppl): S3-7.

9. Bromage PR. Epidural Analgesia. $1^{\text {st }}$ Ed. Philadelphia: WB Saunders; 1978;144.

10. Huskisson EC. Measurement of pain. Lancet 1974 Nov 9; 2(7889):1127-31.

11 Verstraete S, Van de Velde M. Post-cesarean section analgesia. Acta Anaesthesiol Belg. 2012; 63(4):147-167.

12. Gehling M, Tryba M. Risks and side-effects of intrathecal morphine combined with spinal anaesthesia: a meta-analysis. Anaesthesia 06/2009 June; 64(6):64351.

13. Belzarena SD. Clinical effects of intrathecally administered fentanyl in patients undergoing cesarean section. Anesth Analg. 1992 May; 74(5):653-7.

14. Biswas BN, Rudra A, Bose BK, Nath S. Intrathecal fentanyl with hyperbaric bupivacaine improves analgesia during casarean delivery and in early postoperative period. Indian J Anaesth 2002; 46(6):469472 .

15. Hunt CO, Naulty JS, Bader AM, Hauch MA et al. Perioperative analgesia with subarachnoid fentanyl bupivacaine for cesarean delivery. Anesthesiology.1989 Oct; 71 (4):535-40.

16. Braga AA, Frias JA, Braga FS, Poterio GB. Spinal anesthesia for cesarean section. Use of hyperbaric bupivacaine $(10 \mathrm{mg})$ combined with different adjuvants.
Rev Bras Anestesiol. 2012 Nov-Dec;62(6):775-87. doi: 10.1016/S0034-7094(12)70178-2.

17. Wang C, Chakrabarti MK, Whitwam JG. Specific enhancement by fentanyl of the effects of intrathecal bupivacaine on nociceptive afferent but not on sympathetic efferent pathways in dogs. Anesthesiology 1993; 79; 766-73.

18. Benhamou D,Thorin D,Brichant JF,Dailland P, Milon D, Schneider M. Intrathecal Clonidine and Fentanyl with Hyperbaric Bupivacaine improves Analgesia During Cesarean Section. Anesth Analg. 1998;87:609-13.

19. Singh H, Yang J, Thornton K, Giesecke AH. Intrathecal fentanyl prolongs sensory bupivacaine spinal block. Can J Anaesth. 1995, Nov; 42(11):987-91.

20. Ben-David B, Solomon E, Levin H, Admoni H et al. Intrathecal fentanyl with small dose dilute bupivacaine: better analgesia without prolonging recovery. Anesth Analg 1997; 85: 560-65.

21. Chilvers CR, Vaghadia H,Mitchell GW,Merrick PM. Small-dose hypobaric lidocaine-fentanyl spinal anaesthesia for short duration outpatient laparoscopy. II. Optimal fentanyl dose. Anesth Analg. Jan1997; 84(1): 65-70.

22. Sivevski A. Effects of Varying Doses of Plain Bupivacaine with Fentanyl in Patients Undergoing Cesarean Section: Haemodinamics andNeonatal Outcome. Macedonian Journal of Medical Sciences. 2009 Dec 15; 2(4):324-329.

doi:10.3889/MJMS.1857-5773.2009.0076

23. Srivastava U, Kumar A, Gandhi NK, Saxena S et al. Hyperbaric or plain bupivacaine combined with fentanyl for spinal anaesthesia during cesarean delivery. Indian J Anaesth 2004; 48(1):44-46.

24. Chow TC, Cho PH. The influence of small dose intrathecal fentanyl on shivering during transurethral resection of prostate under spinal anesthesia. Acta Anaesthesiol Sin. 1994 Sep; 32(3):165-70.

25. Manullang TR, Viscomi CM, Pace NL. Intrathecal fentanyl is superior to intravenous ondansetron for prevention of perioperative nausea during caesarean delivery with spinal anaesthesia. Anesth Analg 2000 May; 90(5): 1162-6. 
26. Dahlgren G, Hultstrand C, Jakobsson J, Norman M et al. Intrathecal sufentanil, fentanyl, or placebo added to bupivacaine for cesarean section. Anesth Analg. 1997 Dec; 85(6):1288-93.
27. Siddik-Sayyid SM, Aouad MT, Jalbout MI, Zalaket MI et al. Intrathecal versus intravenous fentanyl for supplementation of subarachnoid block during cesarean delivery. Anesth Analg. 2002 Jul; 95(1):209-13.

\section{How to cite this article?}

Uike S, Choudhary S' Jain A. Comparative study of analgesic effect of intrathecal bupivacaine and bupivacaine with fentanyl during and after cesarean delivery. Int J Med Res Rev 2015;3(2):256-262. doi: 10.17511/ijmrr.2015.i3.045. 